\title{
Frequency of Daily Tooth Brushing and Development of any Type of Malignancy
}

\author{
DAIKI KOBAYASHI ${ }^{1,2,3}$, OSAMU TAKAHASHI ${ }^{1,2}$ and TAKURO SHIMBO ${ }^{4}$ \\ ${ }^{1}$ Division of General Internal Medicine, Department of Medicine, St. Luke's International Hospital, Tokyo, Japan; \\ ${ }^{2}$ Department of Epidemiology, St. Luke's International University Graduate School of Public Health, Tokyo, Japan; \\ ${ }^{3}$ Fujita Health University, Toyoake, Japan; \\ ${ }^{4}$ Ohta Nishinouchi Hospital, Koriyama, Japan
}

\begin{abstract}
Background/Aim: The aim of this study was to evaluate the association between the frequency of daily tooth brushing and the development of any type of malignancy. Patients and Methods: We conducted a retrospective longitudinal study, including all adult participants who underwent health check-ups. Primary outcome was the development of any type of malignancy, compared to the frequency of daily tooth brushing, adjusting for potential confounders. Results: A total of 71,449 participants were included and 5,025 participants developed a certain type of malignancy. Not brushing everyday (Odds Ratio $(O R)=1.52$, 95\% Confidence Interval $(C I)=1.03-2.25)$ and brushing once a day $(O R=1.25,95 \% C I=1.16-1.35)$ had significantly higher ORs for the outcome than brushing after every meal, although those who brushed once to twice a day had significantly lower $O R \quad(O R=0.78,95 \% C I=0.72-0.83)$. Conclusion: As the frequency of daily tooth brushing increased, except for brushing after every meal, the development of all types of malignancies decreased.
\end{abstract}

Oral hygiene is now thought to affect not only oral diseases, but also systemic conditions (1). Periodontal diseases caused mainly by poor oral hygiene are said to mediate systemic diseases. For instance, previous studies have reported that periodontal diseases were associated with an increased risk of cardiovascular disease (2) and its risk factors, such as diabetes and dyslipidemia, due to the development of atheromatous plaques $(3,4)$. Others argue that periodontal diseases are associated with systemic infections and

Correspondence to: Daiki Kobayashi, MD, MPH, MBA, Ph.D., Division of General Internal Medicine, Department of Medicine, St. Luke's International Hospital, Tokyo, Japan. Tel/Fax: +81 335415151, e-mail: daikoba@luke.ac.jp

Key Words: Tooth brushing, malignancy, cancer, longitudinal study. treatment of periodontal diseases reduces the incidence of distant infections, such as pneumonia (5). Even adverse pregnancy outcomes (6) and osteoporosis (2) have been suggested to be associated with periodontal diseases.

As a group of systemic diseases related to oral hygiene, certain types of malignancies were evaluated. A previous prospective cohort study among male health professionals showed that people who had a history of periodontal disease had a 1.14-times higher risk of cancer than those without a history of periodontal disease (7). In terms of types of cancer, oral cancer is considered to be associated with oral hygiene directly (8). A large-scale case-control study has indicated that good oral hygiene was inversely associated with all head and neck cancers (9). Others have reported that esophageal, gastric and pancreatic cancers were associated with poor oral hygiene (10-13). Even hematopoietic cancer has been shown to be related to poor oral hygiene (7). Although several studies regarding the association between oral hygiene and malignancies have been published, the majority of them were case-control study designs or focused on specific populations, such as male health professionals or African American females. Large-scale longitudinal studies of a variety of populations are required to confirm these studies.

The aim of this study was to evaluate the association between the frequency of daily tooth brushing and the development of any type of malignancy in a large Japanese cohort.

\section{Patients and Methods}

We conducted a retrospective longitudinal study at St. Luke's International Hospital, a large teaching hospital in Tokyo, Japan, from 2005 to 2018. All adult participants who underwent health check-ups at the center of preventive medicine in the hospital from 2005 to 2012 were included. These participants were asked about their daily tooth brushing frequency as a part of their health checkup. The participants were followed up until December 31, 2018 to evaluate the study outcomes. Those who had a prior history of 
Table I. Baseline characteristics and outcomes by daily tooth-brushing frequency.

\begin{tabular}{|c|c|c|c|c|c|c|}
\hline & $\begin{array}{l}\text { Not everyday } \\
\quad(\mathrm{n}=194)\end{array}$ & $\begin{array}{c}\text { Once } \\
(\mathrm{n}=35,402)\end{array}$ & $\begin{array}{l}\text { Once to twice } \\
(\mathrm{n}=4,243)\end{array}$ & $\begin{array}{l}\text { After every meal } \\
\quad(\mathrm{n}=31,610)\end{array}$ & $\begin{array}{c}\text { Total } \\
(\mathrm{n}=71,449)\end{array}$ & $p$-Value \\
\hline \multicolumn{7}{|l|}{ Outcomes } \\
\hline Development of any cancer & $24(12.4)$ & $2,552(7.2)$ & $218(5.1)$ & $2,231(7.1)$ & $5,025(7.0)$ & $<0.01$ \\
\hline C00-C14: Malignant neoplasms of the & & & & & & \\
\hline lips, oral cavity and pharynx $(n=29)$ & $0(0.0)$ & $16(0.1)$ & $0(0.0)$ & $13(0.1)$ & $29(0.1)$ & 0.55 \\
\hline \multicolumn{7}{|l|}{ C15-C26: Malignant neoplasms } \\
\hline of digestive organs $(n=1,504)$ & $10(5.2)$ & $826(2.3)$ & $62(1.5)$ & $583(1.8)$ & $1,481(2.1)$ & $<0.01$ \\
\hline Esophageal cancer $(n=162)$ & $0(0.0)$ & $94(0.3)$ & $7(0.2)$ & $61(0.2)$ & $162(0.2)$ & 0.16 \\
\hline Gastric cancer $(n=538)$ & $4(2.1)$ & $298(0.8)$ & $23(0.5)$ & $213(0.7)$ & $538(0.8)$ & $<0.01$ \\
\hline $\begin{array}{l}\text { C30-C39: Malignant neoplasms } \\
\text { of respiratory and intrathoracic } \\
\text { organs }(n=523)\end{array}$ & $5(2.6)$ & $297(0.8)$ & $20(0.5)$ & $195(0.6)$ & $517(0.7)$ & $<0.01$ \\
\hline $\begin{array}{l}\text { C40-C41: Malignant neoplasms } \\
\text { of bone and articular cartilage }(n=1)\end{array}$ & $0(0.0)$ & $0(0.0)$ & $0(0.0)$ & $1(0.0)$ & $1(0.0)$ & 0.51 \\
\hline $\begin{array}{l}\text { C43-C44: Melanoma and other } \\
\text { malignant neoplasms of the skin }(n=71)\end{array}$ & $1(0.5)$ & $24(0.1)$ & $5(0.1)$ & $41(0.1)$ & $71(0.1)$ & 0.02 \\
\hline $\begin{array}{l}\text { C45-C49: Malignant neoplasms } \\
\text { of mesothelial and soft tissue }(n=12)\end{array}$ & $0(0.0)$ & $10(0.0)$ & $0(0.0)$ & $2(0.0)$ & $12(0.0)$ & 0.12 \\
\hline \multicolumn{6}{|l|}{ C50-C50: Malignant neoplasms } & $<0.01$ \\
\hline \multicolumn{7}{|l|}{ C51-C58: Malignant neoplasms } \\
\hline \multicolumn{7}{|l|}{ C60-C63: Malignant neoplasms } \\
\hline $\begin{array}{l}\text { C64-C68: Malignant neoplasms } \\
\text { of the urinary tract }(n=235)\end{array}$ & $2(1.0)$ & $122(0.3)$ & $11(0.3)$ & $98(0.3)$ & $233(0.3)$ & 0.21 \\
\hline $\begin{array}{l}\text { C69-C72: Malignant neoplasms } \\
\text { of the eyes, brain and other parts } \\
\text { of central nervous system }(n=9)\end{array}$ & $0(0.0)$ & $6(0.0)$ & $1(0.0)$ & $2(0.0)$ & $9(0.0)$ & 0.27 \\
\hline $\begin{array}{l}\text { C73-C75: Malignant neoplasms of } \\
\text { the thyroid and other endocrine } \\
\text { glands }(n=57)\end{array}$ & $0(0.0)$ & $29(0.1)$ & $4(0.1)$ & $23(.1)$ & $56(0.1)$ & 0.78 \\
\hline $\begin{array}{l}\text { C76-C80: Malignant neoplasms of } \\
\text { ill-defined, other secondary and } \\
\text { unspecified sites }(n=52)\end{array}$ & $0(0.0)$ & $26(0.1)$ & $0(0.0)$ & $26(0.1)$ & $52(0.1)$ & 0.27 \\
\hline $\begin{array}{l}\text { C81-C96: Malignant neoplasms } \\
\text { of lymphoid, hematopoietic } \\
\text { and related tissues }(n=64)\end{array}$ & $0(0.0)$ & $36(0.1)$ & $3(0.1)$ & $24(0.1)$ & $63(0.1)$ & 0.60 \\
\hline D00-D09: In situ neoplasms $(n=28)$ & $0(0.0)$ & $16(0.1)$ & $1(0.0)$ & $9(0.0)$ & $26(0.0)$ & 0.59 \\
\hline Unknown $(n=231)$ & $2(1.0)$ & $121(0.3)$ & $9(0.2)$ & $93(0.3)$ & $225(0.3)$ & 0.11 \\
\hline \multicolumn{7}{|l|}{ Demographics } \\
\hline Age, years (SD) & $48.2(16.8)$ & $46.2(12.0)$ & $43.9(12.4)$ & $45.2(12.0)$ & $45.6(12.0)$ & $<0.01$ \\
\hline Male, n (\%) & $181(93.3)$ & $22,794(64.4)$ & $2,454(57.9)$ & $10,673(33.8)$ & $36,102(50.5)$ & $<0.01$ \\
\hline Family history of any cancer & $66(34.0)$ & $13,902(39.3)$ & $1,776(41.9)$ & $12,542(39.7)$ & $28,286(39.6)$ & $<0.01$ \\
\hline Body mass index, $\mathrm{n}(\%)$ & & & & $<0.01$ & & \\
\hline Underweight $\left(<18.5 \mathrm{~kg} / \mathrm{m}^{2}\right)$ & $5(2.6)$ & $2,229(6.3)$ & $319(7.5)$ & $4,229(13.4)$ & $6,782(9.5)$ & \\
\hline Normal $\left(18.5-24.9 \mathrm{~kg} / \mathrm{m}^{2}\right)$ & $99(51.0)$ & $24,414(69.0)$ & $2,907(68.5)$ & $23,228(73.5)$ & $50,648(70.9)$ & \\
\hline Obese/overweight $\left(25.0 \mathrm{~kg} / \mathrm{m}^{2}<\right)$ & $90(46.4)$ & $8,758(24.7)$ & $1,017(24.0)$ & $4,152(13.1)$ & $14,017(19.6)$ & \\
\hline $\begin{array}{l}\text { Follow-up, days } \\
\text { (interquartile range) }\end{array}$ & $\begin{array}{c}1,487.5 \\
(707-3,005)\end{array}$ & $\begin{array}{c}2,136 \\
(791-3,297)\end{array}$ & $\begin{array}{c}1,448 \\
(770-1,757)\end{array}$ & $\begin{array}{c}2,077 \\
(917-3,296)\end{array}$ & $\begin{array}{c}1,896 \\
(830-3,229)\end{array}$ & $<0.01$ \\
\hline \multicolumn{7}{|l|}{ Social history } \\
\hline Alcohol, n (\%) & & & & & & $<0.01$ \\
\hline Abstainer & $72(37.1)$ & $12,615(35.6)$ & $1,627(38.4)$ & 13,253 (41.9) & $27,567(38.6)$ & \\
\hline Occasional & $21(10.8)$ & $6,155(17.4)$ & $710(16.7)$ & $5,773(18.3)$ & $12,659(17.7)$ & \\
\hline Regular & $101(52.1)$ & $16,632(47.0)$ & $1,906(44.9)$ & $12,584(39.8)$ & $31,223(43.7)$ & \\
\hline Smoking, n (\%) & & & & & & $<0.01$ \\
\hline Never & $71(36.6)$ & $18,456(52.1)$ & $2,440(57.5)$ & $22,188(70.2)$ & $43,155(60.4)$ & \\
\hline Former & $53(27.3)$ & $8,734(24.7)$ & $1,069(25.2)$ & $5,864(18.6)$ & $15,720(22.0)$ & \\
\hline Current & $70(36.1)$ & $8,212(23.2)$ & $734(17.3)$ & $3,558(11.3)$ & $12,574(17.6)$ & \\
\hline
\end{tabular}


Table I. Continued.

\begin{tabular}{|c|c|c|c|c|c|c|}
\hline & $\begin{array}{l}\text { Not everyday } \\
\quad(n=194)\end{array}$ & $\begin{array}{c}\text { Once } \\
(\mathrm{n}=35,402)\end{array}$ & $\begin{array}{l}\text { Once to twice } \\
\quad(n=4,243)\end{array}$ & $\begin{array}{l}\text { After every meal } \\
\quad(\mathrm{n}=31,610)\end{array}$ & $\begin{array}{c}\text { Total } \\
(\mathrm{n}=71,449)\end{array}$ & $p$-Value \\
\hline Exercise, n (\%) & & & & & $<0.01$ & \\
\hline Almost none & $106(54.6)$ & $13,989(39.5)$ & $1,696(40.0)$ & $11,401(36.1)$ & $27,192(38.1)$ & \\
\hline 1-2 times per week & $45(23.2)$ & $13,385(37.8)$ & $1,586(37.4)$ & $11,620(36.8)$ & $26,636(37.3)$ & \\
\hline 3-5 times per week & $24(12.4)$ & $5,012(14.2)$ & $638(15.0)$ & $5,157(16.3)$ & $10,831(15.2)$ & \\
\hline Almost all days & $19(9.8)$ & $3,016(8.5)$ & $323(7.6)$ & $3,432(10.9)$ & $6,790(9.5)$ & \\
\hline \multicolumn{7}{|l|}{ Comorbidities } \\
\hline Hypertension, n (\%) & $27(13.9)$ & $2,975(8.4)$ & $344(8.1)$ & $1,932(6.1)$ & $5,278(7.4)$ & $<0.01$ \\
\hline Diabetes, n (\%) & $17(8.8)$ & $998(2.8)$ & $13(0.3)$ & $544(1.7)$ & $1,572(2.2)$ & $<0.01$ \\
\hline Dyslipidemia, n (\%) & $14(7.2)$ & $1,663(4.7)$ & $222(5.2)$ & $1,255(4.0)$ & $3,154(4.4)$ & $<0.01$ \\
\hline
\end{tabular}

Table II. Adjusted odds ratio for the development of any malignancy by daily tooth-brushing frequency.

\begin{tabular}{|c|c|c|c|c|}
\hline & \multicolumn{4}{|c|}{ Adjusted odds ratio (95\% confidence interval) } \\
\hline & \multicolumn{4}{|c|}{ Daily tooth-brushing frequency } \\
\hline & Not everyday & Once a day & Once to twice a day & After every meal \\
\hline Model 1 & $1.60(1.08-2.36)$ & $1.28(1.19-1.37)$ & $0.78(0.72-0.84)$ & Reference \\
\hline Model 2 & $1.53(1.03-2.26)$ & $1.26(1.17-1.35)$ & $0.77(0.72-0.83)$ & Reference \\
\hline Model 3 & $1.51(1.02-2.24)$ & $1.25(1.16-1.35)$ & $0.78(0.72-0.84)$ & Reference \\
\hline Model 4 & $1.52(1.03-2.25)$ & $1.25(1.16-1.35)$ & $0.78(0.72-0.83)$ & Reference \\
\hline
\end{tabular}

Model 1 was adjusted for time and participants' age and sex; model 2 was adjusted for social history (smoking, alcohol consumption and exercise) and body mass index in addition to the covariates in model 1; model 3 was adjusted for comorbidities (hypertension, diabetes and dyslipidemia) in addition to the covariates in model 2; and model 4 was adjusted for family history of any cancer in addition to the covariates in model 3 . The numbers in bold indicate that the $p$-value was less than 0.05 .

malignancy at the time of their first visit to the center were excluded from this study. Our primary outcome was the development of any type of malignancy during the follow-up period, and our secondary outcomes were the development of classified malignancies based on the International Classification of Diseases 10 (ICD-10) (14). We compared outcomes by frequency of daily tooth brushing, adjusting for potential confounders.

St Luke's International Hospital Ethics Committee Institutional Review Board approved this study (approved number: 18-R203. Comprehensive approvals for studies about social habits).

Outcomes. Our primary outcome was any type of malignancy during the follow-up period. Information about the development of malignancies was collected based on the following three approaches: electronical medical records from the hospital, cancer registry from the hospital, and participants' self-report. Electronical medical records from the hospital contained all information about malignancies that were both clinically and pathologically diagnosed at the hospital. The managers of the cancer registry of the hospital collected all information about the malignancies diagnosed at other hospitals by phone-call or referral documents. Participants were also asked about their history of malignancies as a part of health checkup. Malignancies were categorized into 16 groups based on ICD-10 as a secondary outcome. Among C15-C26, malignant neoplasms of digestive organs in ICD-10, esophagus cancer and gastric cancer were independently evaluated because previous studies cautioned the association of an increased risk with frequency of daily tooth brushing $(12,13)$. For those who developed malignancies multiple times during follow-up, only the data from the first malignancy development were used for analyses.

Frequency of daily tooth brushing. As part of the routine questionnaire, participants who underwent health check-ups from 2005 to 2012 were asked about their daily tooth brushing frequency on a typical day. Based on the response, we classified the respondents into four groups: not every day, once a day, once to twice a day, and every after meal. We defined the group who brushed their teeth every after meal as the reference group. Information about the frequency of daily tooth brushing was obtained at each visit, so tooth-brushing frequency was considered a time-dependent variable.

Covariates. As covariates of the association between frequency of daily tooth brushing and the development of a malignancy, we collected data about participants' demographics, social history, comorbidities and family history of malignancies. In terms of 
Table III. Adjusted odds ratio for the development of each malignancy by daily tooth-brushing frequency.

\begin{tabular}{|c|c|c|c|c|}
\hline & \multicolumn{4}{|c|}{ Adjusted odds ratio ( $95 \%$ confidence interval) } \\
\hline & \multicolumn{4}{|c|}{ Frequency of daily tooth brushing } \\
\hline & Not everyday & Once a day & Once to twice a day & After every meal \\
\hline $\begin{array}{l}\text { C00-C14: Malignant neoplasms of the lips, } \\
\text { oral cavity and pharynx }(n=29)\end{array}$ & - & $2.41(0.89-6.53)$ & $0.73(0.29-1.82)$ & Reference \\
\hline $\begin{array}{l}\text { C15-C26: Malignant neoplasms of } \\
\text { digestive organs }(n=1,481)\end{array}$ & $1.53(0.87-2.70)$ & $1.28(1.11-1.46)$ & $0.77(0.67-0.88)$ & Reference \\
\hline Esophageal cancer $(n=162)$ & - & $1.11(0.74-1.66)$ & $0.74(0.50-1.10)$ & Reference \\
\hline Gastric cancer $(n=538)$ & $1.34(0.54-3.30)$ & $1.20(0.97-1.49)$ & $0.79(0.63-1.00)$ & Reference \\
\hline $\begin{array}{l}\text { C30-C39: Malignant neoplasms of respiratory } \\
\text { and intrathoracic organs }(n=517)\end{array}$ & $1.68(0.62-4.61)$ & $1.40(1.10-1.78)$ & $0.97(0.78-1.20)$ & Reference \\
\hline $\begin{array}{l}\text { C40-C41: Malignant neoplasms of bone } \\
\text { and articular cartilage }(n=1)\end{array}$ & - & - & - & Reference \\
\hline $\begin{array}{l}\text { C43-C44: Melanoma and other malignant } \\
\text { neoplasms of the skin }(n=71)\end{array}$ & $2.13(0.28-16.0)$ & $0.65(0.33-1.28)$ & $0.47(0.26-0.85)$ & Reference \\
\hline $\begin{array}{l}\text { C45-C49: Malignant neoplasms of } \\
\text { mesothelial and soft tissue }(n=12)\end{array}$ & - & $5.67(1.45-22.1)$ & $0.36(0.04-3.38)$ & Reference \\
\hline $\begin{array}{l}\text { C50-C50: Malignant neoplasms of breast tissue } \\
(\mathrm{n}=1,043)\end{array}$ & - & $1.20(1.02-1.42)$ & $0.79(0.68-0.92)$ & Reference \\
\hline C51-C58: Malignant neoplasms of female genital organs $(n=433)$ & - & $1.30(1.02-1.65)$ & $1.13(0.88-1.44)$ & Reference \\
\hline C60-C63: Malignant neoplasms of male genital organs $(n=774)$ & $0.86(0.35-2.11)$ & $1.66(1.38-2.01)$ & $0.79(0.66-0.96)$ & Reference \\
\hline $\begin{array}{l}\text { C64-C68: Malignant neoplasms of the urinary tract } \\
(n=233)\end{array}$ & $1.39(0.34-5.73)$ & $1.18(0.85-1.64)$ & $0.70(0.50-0.99)$ & Reference \\
\hline $\begin{array}{l}\text { C69-C72: Malignant neoplasms of the eyes, brain and } \\
\text { other parts of central nervous system }(n=9)\end{array}$ & - & $10.9(1.71-69.9)$ & $1.46(0.24-8.97)$ & Reference \\
\hline $\begin{array}{l}\text { C73-C75: Malignant neoplasms of the thyroid and } \\
\text { other endocrine glands }(n=56)\end{array}$ & - & $1.38(0.67-2.84)$ & $1.17(0.62-2.24)$ & Reference \\
\hline $\begin{array}{l}\text { C76-C80: Malignant neoplasms of ill-defined, other } \\
\text { secondary and unspecified sites }(n=52)\end{array}$ & - & $1.93(0.98-3.80)$ & $0.45(0.20-0.99)$ & Reference \\
\hline $\begin{array}{l}\text { C81-C96: Malignant neoplasms of lymphoid, hematopoietic } \\
\text { and related tissues }(n=63)\end{array}$ & $5.48(0.71-42.0)$ & $1.60(0.86-2.97)$ & $0.71(0.36-1.42)$ & Reference \\
\hline D00-D09: In situ neoplasms $(\mathrm{n}=26)$ & - & $1.99(0.78-5.08)$ & $2.97(0.95-9.24)$ & Reference \\
\hline Unknown $(\mathrm{n}=225)$ & $1.22(0.17-8.81)$ & $1.12(0.82-1.53)$ & $0.68(0.47-0.98)$ & Reference \\
\hline
\end{tabular}

Analyses were adjusted for time and participants' age and sex, social history, body mass index, comorbidities and family history of any cancer. The number in bold indicates that the $p$-value was less than 0.05 .

demographic data, participants' age and sex were obtained. Height and weight measured by trained staff were used to calculate body mass index (BMI), which was categorized into three groups based on the World Health Organization criteria for Asian populations: underweight $\left(B M I<18.5 \mathrm{~kg} / \mathrm{m}^{2}\right)$, normal $\left(18.5-24.9 \mathrm{~kg} / \mathrm{m}^{2}\right)$ and obese/overweight $\left(\geq 25.0 \mathrm{~kg} / \mathrm{m}^{2}\right)(15)$. Family history of any malignancy in second degree relatives was also obtained as part of the questionnaire. Social history included smoking status (never, former or current), alcohol consumption (abstainer, occasional drinker or regular drinker) and exercise habits (almost none, 1-2 times a week, 3-5 times a week or almost all days). Comorbidities included a self-reported current history of hypertension, diabetes or dyslipidemia. All these datapoints were also obtained at each follow-up visit and were considered time-dependent variables.

Statistical methods. We compared the participants' baseline characteristics and outcomes with baseline frequency of daily tooth brushing using bivariable analyses. Continuous variables, except for follow-up periods, were analyzed with analysis of variance (ANOVA). The Kruskal-Wallis test was applied to analyze the follow-up periods because this variable was not normally distributed. The chi-squared test was applied to most categorical variables, and Fisher's exact test was applied to variables with relatively small numbers.

Then, multivariate longitudinal analyses with generalized estimating equation (GEE) models were performed to calculate odds ratios (ORs) of malignancies by frequency of daily tooth brushing. We used a binomial distribution and the logit link function for the model. Different covariates were applied to different models to find consistent results; model 1 was adjusted for time and the participants' age and sex; model 2 was adjusted for social history and BMI in addition to the covariates in model 1; model 3 was adjusted for comorbidities in addition to the covariates in model 2; and model 4 was adjusted for family history of cancer in addition to the covariates in model 3 . As a secondary analysis, the same process was applied to each type of malignancy. Because both the frequency of daily tooth brushing and the development of a 
malignancy were considered to be different between sexes, we examined the interaction term between the frequency of daily tooth brushing and sex on the outcome. If the interaction term was statistically significant, then we would analyze the data after stratifying by sex. In addition, to evaluate the association with malignancies other than those that have previously been reported, we performed subanalysis with the data of any malignancy except for $\mathrm{C} 00-\mathrm{C} 14$ ( malignant neoplasms of the lips, oral cavity and pharynx; esophageal cancer; and gastric cancer, which were reported to be associated with oral hygiene in previous studies).

All analyses were performed by using STATA 14 in 2019 (STATA Corp., College Station, TX, USA).

\section{Results}

A total of 71,449 participants were included in this study. The mean age (standard deviation) was 45.6 (12.0) years, and $36,102(50.5 \%)$ of the participants were male. Table I shows the baseline characteristics based on the frequency of daily tooth brushing. As the daily tooth-brushing frequency decreased, participants were more likely to be older, male and obese/overweight. Additionally, as the frequency of daily tooth brushing decreased, unhealthier lifestyles, such as regular drinking, current smoking and less exercise, were more common. All comorbidities, including hypertension, diabetes and dyslipidemia, increased as the frequency of daily tooth brushing decreased.

During a median follow-up period of 1,896 (interquartile range $=830-3,229)$ days, 5,025 participants $(7.0 \%)$ developed some type of malignancy. The development of malignancies and their types according baseline frequency of daily tooth brushing are summarized in Table I. In multivariate longitudinal analyses after adjusting for potential covariates, not brushing teeth everyday $(\mathrm{OR}=1.52,95 \%$ confidence interval $(\mathrm{CI})=1.03-2.25$ in model 4$)$ and brushing teeth once a day $(\mathrm{OR}=1.25,95 \% \mathrm{CI}=1.16$ 1.35 in model 4) had significantly higher ORs for the development of any type of malignancy compared to brushing teeth after every meal (Table II). However, those who brushed their teeth once to twice a day had significantly lower ORs for any type of malignancy than those who brushed their teeth after every meal $(\mathrm{OR}=0.78,95 \% \mathrm{CI}=0.72-0.83$ in model 4$)$. There was no interaction between daily tooth-brushing frequency and sex on the development of malignancies $(p=0.37)$.

In secondary analyses of each type of malignancy, similar associations were observed for most types of malignancies, except for C51-C58 (malignant neoplasms of female genital organs) (Table III). Although a sufficient number of events was observed in C51-C58 (malignant neoplasms of female genital organs) $(n=433)$, those who brushed their teeth once to twice a day had a slightly higher, but not statistically significant, OR for the malignancies than those who brushed their teeth after every meal $(\mathrm{OR}=1.13,95 \% \mathrm{CI}=0.88-1.44)$.

Even after excluding the data about the development of C00-C14 (malignant neoplasms of the lips, oral cavity and pharynx, esophageal cancer, and gastric cancer) the association of not brushing teeth every day and brushing teeth once a day with a greater development of any type of malignancy and brushing teeth once to twice a day with a lower development of malignancies than brushing teeth every after meal were still observed $(\mathrm{OR}=1.62,95 \% \mathrm{CI}=1.05$ 2.49 for not brushing teeth every day; $\mathrm{OR}=1.26$, $95 \% \mathrm{CI}=1.16-1.37$ for brushing teeth once a day; $\mathrm{OR}=0.78$, $95 \% \mathrm{CI}=0.72-0.84$ for brushing teeth once to twice a day).

\section{Discussion}

Our study demonstrated that not brushing teeth every day and brushing teeth once a day were associated with an increased risk of developing any malignancy, not only head, neck or upper gastrointestinal cancers, compared to brushing teeth after every meal. In contrast, brushing teeth once to twice a day was associated with a lower risk of developing any malignancy than brushing teeth after every meal.

Our finding that less frequent daily tooth brushing was associated with an increased risk for the development of malignancies supported the findings of previous studies and extended the evidence to other types of malignancies that were not evaluated in previous studies. A previous large prospective cohort study among U.S. male health professionals suggested that low oral hygiene was associated with an increased risk for lung, hematopoietic, kidney and prostate cancers (7). Another cohort study among African American women reported that poor oral health was related to pancreatic cancer (11). The association with these malignancies was still observed in our study, although some were not statistically significant, probably due to the limited number of events. In our study, other types of malignancies, such as C45-C49 (malignant neoplasms of mesothelial and soft tissue), C50-C50 (malignant neoplasms of breast tissue), C51-C58 (malignant neoplasms of female genital organs) and C73-C75 (malignant neoplasms of thyroid and other endocrine glands), tended to be observed more frequently among those who brushed their teeth less frequently. Based on the results, the frequency of tooth brushing may be associated with malignancies regardless of type.

Two main underlying mechanisms were proposed for the association: local inflammation and systemic inflammation due to alterations in the oral microbiota and periodontal diseases $(10,16)$. Periodontal disease is now considered not only a local infection but also a systemic disease, which may play some roles in the development of malignancies (7). In fact, patients with periodontal infection had increased circulating inflammatory markers, such as c-reactive protein and fibrinogen (17-19). In addition, Porphyromonas gingivalis ( $P$. gingivalis), which is one of the most common pathogens causing periodontal diseases, was said to play some roles in carcinogenesis and cancer growth through the 
immune-response pathway $(11,20,21)$. Local inflammation associated with this mechanism may be associated with head and neck cancers, including cancers of the oral cavity, and systemic inflammation may be associated with distant malignancies, such as pancreatic cancer. Given that our study revealed that the frequency of tooth brushing was inversely associated with malignancies regardless of type, systemic inflammation may have a higher impact on carcinogenesis.

The reasons why brushing teeth once to twice a day was associated with a lower risk of malignancies than brushing teeth after every meal in our study are unclear. However, the difference in the definition of frequency of tooth brushing might play some roles in the result. Most previous studies divided the frequency into daily, less than daily and never (11-13), whereas our study divided the frequency into not every day, once a day, once to twice a day, and after every meal. In other words, the individuals in our sample may have advanced oral hygiene awareness compared to the awareness of participants in other studies. Because some experts have cautioned against excessive tooth brushing (22), appropriate oral care might be recommended.

Our study has certain limitations. Our study assessed the selfreported frequency of daily tooth brushing, but did not include an objective evaluation of oral hygiene, including periodontal diseases. Although the frequency of tooth brushing was reported to be associated with the prevalence of periodontal diseases (23), the direct impact of periodontal diseases on malignancies cannot be assessed. Second, the median follow-up of 1,896 days (5.2 years) may be relatively short to evaluate the development of malignancies. Although a sufficient number of events occurred in terms of any type of malignancy, additional events are required to evaluate rare malignancies. Finally, almost all our study's population was Japanese, so we may not be able to generalize the results to populations of other races.

\section{Conclusion}

As the daily tooth-brushing frequency increased, with the exception of brushing every after meal, the development of any type of malignancy decreased. Compared to brushing after every meal, brushing once to twice a day may be associated with a lower risk of malignancies. Additional studies regarding the effects of brushing after every meal are required.

\section{Conflicts of Interest}

The Authors declare no conflicts of interest regarding this study.

\section{Authors' Contributions}

All Authors contributed to the design and conduct of the study, data collection and management, interpretation of the data; and preparation, review, and approval of the manuscript. DK had full access to the data and conducted the statistical analysis.

\section{References}

1 Li X, Kolltveit KM, Tronstad L and Olsen I: Systemic diseases caused by oral infection. Clin Microbiol Rev 13(4): 547-558, 2000. PMID: 11023956.

2 Kim J and Amar S: Periodontal disease and systemic conditions: A bidirectional relationship. Odontology 94(1): 10-21, 2006. PMID: 16998613. DOI: 10.1007/s10266-006-0060-6

3 Kelishadi R, Mirmoghtadaee P, Qorbani M, Motlagh ME, Heshmat R, Taslimi M, Mahmoudarabi M, Ardalan G and Larijani B: Tooth brushing and cardiometabolic risk factors in adolescents: Is there an association? The caspian-iii study. Int J Prev Med 4(3): 271-278, 2013. PMID: 23626883.

4 Fentoglu O and Bozkurt FY: The bi-directional relationship between periodontal disease and hyperlipidemia. Eur J Dent 2(2): 142-146, 2008. PMID: 19212526.

5 Shen TC, Chang PY, Lin CL, Chen CH, Tu CY, Hsia TC, Shih $\mathrm{CM}$, Hsu WH, Sung FC and Kao CH: Periodontal treatment reduces risk of adverse respiratory events in patients with chronic obstructive pulmonary disease: A propensity-matched cohort study. Medicine (Baltimore) 95(20): e3735, 2016. PMID: 27196497. DOI: 10.1097/MD.0000000000003735

6 Offenbacher S, Lieff S, Boggess KA, Murtha AP, Madianos PN, Champagne CM, McKaig RG, Jared HL, Mauriello SM, Auten RL Jr., Herbert WN and Beck JD: Maternal periodontitis and prematurity. Part i: Obstetric outcome of prematurity and growth restriction. Ann Periodontol 6(1): 164-174, 2001. PMID: 11887460. DOI: 10.1902/annals.2001.6.1.164

7 Michaud DS, Liu Y, Meyer M, Giovannucci E and Joshipura K: Periodontal disease, tooth loss, and cancer risk in male health professionals: A prospective cohort study. Lancet Oncol 9(6): 550-558, 2008. PMID: 18462995. DOI: 10.1016/S1470-2045 (08)70106-2

8 Gupta B, Bray F, Kumar N and Johnson NW: Associations between oral hygiene habits, diet, tobacco and alcohol and risk of oral cancer: A case-control study from india. Cancer Epidemiol 51: 7-14, 2017. PMID: 28968558. DOI: 10.1016/ j.canep.2017.09.003

9 Hashim D, Sartori S, Brennan P, Curado MP, Wunsch-Filho V, Divaris K, Olshan AF, Zevallos JP, Winn DM, Franceschi S, Castellsague X, Lissowska J, Rudnai P, Matsuo K, Morgenstern H, Chen C, Vaughan TL, Hofmann JN, D'Souza G, Haddad RI, Wu H, Lee YC, Hashibe M, Vecchia CL and Boffetta P: The role of oral hygiene in head and neck cancer: Results from international head and neck cancer epidemiology (inhance) consortium. Ann Oncol 27(8): 1619-1625, 2016. PMID: 27234641. DOI: $10.1093 /$ annonc/mdw224

10 Meyer MS, Joshipura K, Giovannucci E and Michaud DS: A review of the relationship between tooth loss, periodontal disease, and cancer. Cancer Causes Control 19(9): 895-907, 2008. PMID: 18478344. DOI: 10.1007/s10552-008-9163-4

11 Gerlovin H, Michaud DS, Cozier YC and Palmer JR: Oral health in relation to pancreatic cancer risk in african american women. Cancer Epidemiol Biomarkers Prev 28(4): 675-679, 2019. PMID: 30923045. DOI: 10.1158/1055-9965.EPI-18-1053

12 Shakeri R, Malekzadeh R, Etemadi A, Nasrollahzadeh D, AbediArdekani B, Khoshnia M, Islami F, Pourshams A, Pawlita M, Boffetta P, Dawsey SM, Kamangar F and Abnet CC: Association of tooth loss and oral hygiene with risk of gastric adenocarcinoma. Cancer Prev Res (Phila) 6(5): 477-482, 2013. PMID: 23503651. DOI: 10.1158/1940-6207.CAPR-12-0491 
13 Chen H, Nie S, Zhu Y and Lu M: Teeth loss, teeth brushing and esophageal carcinoma: A systematic review and meta-analysis. Sci Rep 5: 15203, 2015. PMID: 26462879. DOI: 10.1038/ srep 15203

14 World health organization. The international classification of diseases. 2016; http://www.Who.Int/classifications/icd/icdonline versions/en/. Accessed march 26, 2019.,

15 Consultation WHOE: Appropriate body-mass index for asian populations and its implications for policy and intervention strategies. Lancet 363(9403): 157-163, 2004. PMID: 14726171. DOI: $10.1016 / \mathrm{S} 0140-6736(03) 15268-3$

16 Bui FQ, Almeida-da-Silva CLC, Huynh B, Trinh A, Liu J, Woodward J, Asadi $\mathrm{H}$ and Ojcius DM: Association between periodontal pathogens and systemic disease. Biomed J 42(1): 27 35, 2019. PMID: 30987702. DOI: 10.1016/j.bj.2018.12.001

17 Joshipura KJ, Wand HC, Merchant AT and Rimm EB: Periodontal disease and biomarkers related to cardiovascular disease. J Dent Res 83(2): 151-155, 2004. PMID: 14742654. DOI: $10.1177 / 154405910408300213$

18 Loos BG: Systemic markers of inflammation in periodontitis. J Periodontol 76(11 Suppl): 2106-2115, 2005. DOI: 10.1902/jop. 2005.76.11-S.2106

19 Amabile N, Susini G, Pettenati-Soubayroux I, Bonello L, Gil JM, Arques S, Bonfil JJ and Paganelli F: Severity of periodontal disease correlates to inflammatory systemic status and independently predicts the presence and angiographic extent of stable coronary artery disease. J Intern Med 263(6): 644-652, 2008. PMID: 18205762. DOI: 10.1111/j.1365-2796.2007. 01916.x
20 Su L, Xu Q, Zhang P, Michalek SM and Katz J: Phenotype and function of myeloid-derived suppressor cells induced by porphyromonas gingivalis infection. Infect Immun 85(8), 2017. PMID: 28533469. DOI: 10.1128/IAI.00213-17

21 Binder Gallimidi A, Fischman S, Revach B, Bulvik R, Maliutina A, Rubinstein AM, Nussbaum G and Elkin M: Periodontal pathogens porphyromonas gingivalis and fusobacterium nucleatum promote tumor progression in an oral-specific chemical carcinogenesis model. Oncotarget 6(26): 22613-22623, 2015. PMID: 26158901. DOI: 10.18632/oncotarget.4209

22 Wiegand A and Schlueter N: The role of oral hygiene: Does tooth brushing harm? Monogr Oral Sci 25: 215-219, 2014. PMID: 24993269. DOI: 10.1159/000360379

23 Lertpimonchai A, Rattanasiri S, Arj-Ong Vallibhakara S, Attia J and Thakkinstian A: The association between oral hygiene and periodontitis: A systematic review and meta-analysis. Int Dent J 67(6): 332-343, 2017. PMID: 28646499. DOI: 10.1111/idj.12317

Received June 26, 2019

Revised July 2, 2019

Accepted July 3, 2019 